\title{
Syntheses and crystal structures of new ruthenium(II) organometallic compounds with NSAID type ligands
}

\author{
M.Schoeller, J. Moncol' \\ Department of inorganic chemistry, Institute of inorganic chemistry, technology and materials, Faculty of chemical and food \\ technology, Slovak University of Technology in Bratislava, Radlinského 9, 81237 Bratislava, Slovakia \\ martin.schoeller@stuba.sk
}

Ruthenium compounds play key role in development of new cytostatic agents in cancer therapy. Main features for choosing ruthenium are: a) possibility of existence at least in two oxidation states under physiological conditions (+II, +III), b) variable kinetic inertness with respect to the oxidation state which allows activation by reduction mechanism, c) ability to mimic iron in transport pathways [13]. NSAIDs as ligands introduce interesting strategy of cytostatic effect tuning. Complexes of NSAIDs with ruth enium can affect pathways of angiogenesis and production of metastases [4]. Increased cytotoxicity of some compounds can be explained by increased lipophilicity and therefore also with cellular input $[4,5]$.

In order to prepare new ruthenium(II) compounds we chose $\left[\mathrm{Ru}_{2}(p \text {-cymene })_{2} \mathrm{Cl}_{4}\right]$ organometallic precursor and NSAIDs as ligands. Figure 1 shows new four-nuclear ruthenium(II) organometallic complex with new single bond between ruthenium(II) and 5fluorosalicylate carbon. Single crystal diffraction data were collected with four-cycle Stoe StadiVari diffractometer with PILATUS3R $300 \mathrm{~K}$ hybrid pixel array detector using microfocused X-ray source Xenocs Genix3D Cu HF (CuKa, $\lambda=1.54186 \AA)$. The crystal structures were solved by direct method using SHELXS [6]. The crystal structures were drawn with OLEX2 [7]. Supramolecular structures were analysed using CrystalExplorer [8].

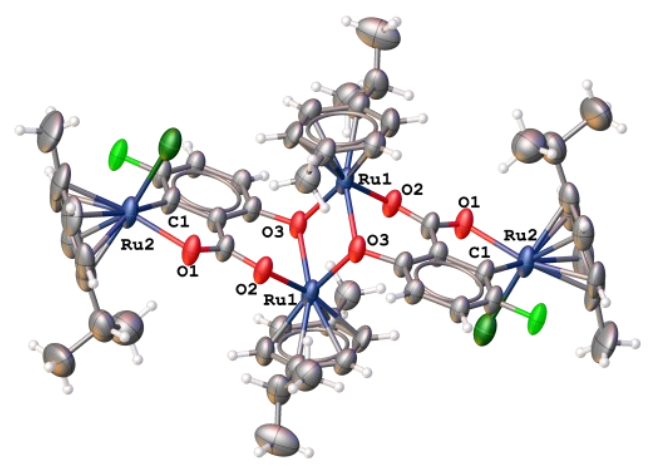

Figure 1. Molecular structure of four-nuclear ruthenium(II) compound with formula $\left[\mathrm{Ru}_{4}(p \text {-cymene })_{4}(5 \text {-Fluoro-SA })_{2} \mathrm{Cl}_{2}\right]$.

[1] Housecroft, E. C., Sharpe, G. A. (2005). Inorganic chemistry. Essex: Pearson Education Limited.

[2] Dabrowiak, J. C. (2017). Metals in Medicine. John Wiley \& Sons.

[3] Alessio, E. (2011). Bioinorganic Medicinal Chemistry. John Wiley \& Sons.

[4] Srivastava, P., Mishra, R., Verma, M., Sivakumar, M. Patra, K. A. (2019). Polyhedron, 172, 132-140.

[5] Chen, J., Zhang, Y., Jie, X., She, J., Dongye, G., Zhong, Y. Deng, Y. Wang, J., Guo, B., Chen, L. (2019). J. Inorg. Biochem., 193, $112-123$.

[6] Sheldrick, G. M. (2015). Acta Crystalogr., A71, 3-8.

[7] Dolomanov, O. V., Bourhis, L. J., Gildea, R. J., Howard, J. A. K., Puschmann, H. (2009). J. Appl. Cryst., 42, 339-341

[8] Turner, M. J., McKinnon, J. J., Wolff, S. K., Gromwood, D. J., Spackman, P. R., Jayalitaka, D., Spackman, M. A. (2017) CrystalExplorer 17.5, University of Western Australia, Australia

\section{Keywords: ruthenium(II); NSAID; cytostatic agents; p-cymene}

This work has been created with the support of the Ministry of Education, Science, Research and Sport of SR within the Research and Development Operational Programme for the project "University Science Park of STU Bratislava, ITMS 26240220084, co-funded by the European Regional Development Found. Grand Agency of Slovak Republic (VEGA 1/0639/18, VEGA 1/0482/20, APVV 19-0087) is gratefully acknowledged for their financial support.

Acta Cryst. (2021), A77, C1035 